\title{
AVALIAÇÃO DA QUALIDADE DA ÁGUA DESTINADA AO CONSUMO HUMANO EM INSTITUIÇÃO DE ENSINO
}

\author{
Danilo Aparecido Gatto CAMPOS ${ }^{1}$ \\ Janaina de Melo FRANCO ${ }^{2}$ \\ Benício Alves de ABREU FILHO \\ Rosângela BERGAMASCO ${ }^{4}$ \\ Natália Ueda YAMAGUCHI ${ }^{5,6^{*}}$
}

\footnotetext{
${ }^{1}$ Graduando do curso de Engenharia Ambiental e Sanitária do Centro Universitário de Maringá - UNICESUMAR, danilo_gatto_15@hotmail.com

${ }^{2}$ Mestre, Docente do curso de Engenharia Civil do Centro Universitário de Maringá - UNICESUMAR, janydemelo@gmail.com

${ }^{3}$ Doutor, Docente do curso de Pós-Graduação de Ciências de Alimentos da Universidade Estadual de Maringá - UEM, baafilho@uem.br

${ }^{4}$ Doutora, Docente do curso de Pós-Graduação de Engenharia Química da Universidade Estadual de Maringá - UEM, rosangela@deq.uem.br

${ }^{5}$ Doutora, Docente do Curso de Mestrado em Tecnologias Limpas do Centro Universitário de Maringá UNICESUMAR, Av. Guedner, 1610 - Jardim Aclimação, Maringá - PR, 87050-390, Tel: 044-3027-6360 ramal: 1178 natalia.yamaguchi@unicesumar.edu.br

${ }^{6}$ Doutora, Pesquisadora do Instituto de Ciência, Tecnologia e Inovação - ICETI
}

Recebido em: 22/092016 - Aprovado em: 15/04//2017 - Disponibilizado em: 01/07/2017

\begin{abstract}
RESUMO:
A água destinada ao consumo humano nem sempre é de qualidade assegurada. Isso ocorre devido fatores como deficiência no sistema de distribuição de água tratada e no tratamento da mesma. A qualidade da água foi monitorada em 21 pontos (bebedouros, poço e torneira) de uma instituição de ensino na cidade de Maringá, por meio de análises físico-químicas e bacteriológica. Os resultados das análises foram confrontados com padrões de potabilidade da água no Brasil. A presente pesquisa revelou que os metais alumínio, cádmio, chumbo e ferro encontraram-se em concentrações acima do valor máximo permitido e as concentrações de cloro apresentaram-se abaixo do valor mínimo exigido $(<0,2$ $\mathrm{mg} / \mathrm{L}$ ), dessa forma havendo a presença de coliformes totais. Os resultados obtidos foram insatisfatórios, sendo necessárias ações corretivas para assegurar a qualidade da água destinada ao consumo humano.
\end{abstract}

Palavras-chave: Cloro; Coliformes; Metais; Qualidade da água, Controle higiênico-sanitário.

\section{EVALUATION OF WATER QUALITY FOR HUMAN CONSUMPTION IN AN EDUCATION INSTITUTION}

\begin{abstract}
:
Water destined to human consumption is not always of assured quality. This is due to factors such as deficiency in the treated water distribution system and the treatment itself. The water quality was monitored at 21 points (drinking fountain, well and tap) from an education institution in Maringa city, through physical-chemical, metals and bacteriological analysis. The data analyzes were confronted with standards for drinking water in Brazil. This research revealed that the metals aluminum, cadmium, lead and iron were found in concentrations above the maximum allowed and chlorine concentrations were below the minimum value required by regulation $(<0.2 \mathrm{mg} / \mathrm{L})$, thus having the presence of total coliforms. The results were unsatisfactory, requiring corrective actions to ensure the quality of water for human consumption.
\end{abstract}

Keywords: Chlorine; Coliforms; Metals; Water quality; Hygiene and sanitary control. 


\section{INTRODUÇÃO}

Em princípio, a qualidade da água e as impurezas adicionais que ela apresenta deveria ser determinada por condições naturais do meio ambiente. Porém, as atividades humanas, causado pelo aumento e expansão demográfica e atividades econômicas na indústria e agricultura, têm sido o fator determinante da qualidade da água superficial e subterrânea (DODDS et al., 2013). Os consequentes problemas de poluição ocorreram e cresceram de forma constante durante um longo período de tempo. A descarga de efluentes, o uso de produtos químicos sintéticos, tais como inseticidas e herbicidas, erosão de solos, dentre outros, têm influenciado grandemente no aumento da quantidade de impurezas presentes na água (FU et al., 2013).

Por centenas de anos a pesquisa em relação à água potável se tornou um campo de estudo multidisciplinar que cobre um grande espectro incluindo ciências ambientais, bioquímica, biologia molecular e medicina. Hoje, existem muitos problemas incluindo contaminantes orgânicos, farmacêuticos, metais pesados e compostos arsênicos que têm chamado atenção (WANG et al., 2010).

A abundancia de compostos orgânicos, compostos químicos, metais, nitritos, nitratos e compostos radioativos na água podem causar efeitos prejudiciais à saúde humana, tais como câncer, entre outras doenças crônicas (IKEM et al., 2002).
Estudos sugerem que a exposição ao cádmio podem causar danos renais, problemas de osteoporose, doenças cardiovasculares, além de ser classificado como carcinogênico. O chumbo também pode causar complicações renais e neoplasias, além de apresentar indícios de ser neurotóxico aos humanos (JÄRUP, 2003).

O alumínio não é essencial para vida, pelo contrário, ele é estabelecido como uma neurotoxina, e é suspeito de ser responsável por várias doenças neuro-degenerativas, como por exemplo a doença de Alzheimer, esclerose lateral amiotrófica, doença de Parkinson, dentre outras (KAWAHARA et al., 2011). Assim como os outros metais pesados, o manganês, ferro, zinco, e cobre, podem causar efeitos prejudiciais aos seres humanos quando em concentrações elevadas (DIETER et al., 2005; WASSERMAN et al., 2006; ZATTA et al., 2003).

A qualidade biológica da água é outro termo que assola mundialmente em questão da qualidade da água para consumo humano, já que a presença de microrganismos podem ser causadores de doenças infecciosas. Doenças relacionadas à contaminação de água potável constitui um grande encargo sobre a saúde pública. O principal risco para a saúde é de ingestão de água contaminada que contêm agentes patogênicos que causam doenças infecciosas tais como a cólera e outras doenças diarréicas, disenterias e febres entéricas, sendo que a diarréia continua sendo 
a principal causa de morte de crianças de baixa renda (LIU et al., 2012; OMS, 2011).

O presente trabalho teve como objetivo avaliar 21 pontos, entre bebedouros, torneira e caixa d'água de uma instituição de ensino de Maringá para verificar a qualidade da água destinada ao consumo humano, sabendo-se dos riscos à saúde humana causados pela água quando consumida sem os padrões de qualidade regulamentados.

\section{MATERIAIS E MÉTODOS}

Dentre os locais de amostragem, foram selecionados 19 bebedouros, uma torneira e a caixa d'água de uma instituição de ensino da cidade de Maringá - PR.

Os ensaios bacteriológicos foram realizados com coletas de $150 \mathrm{~mL}$ da amostra de água em recipientes plásticos, acrescidos de $2,5 \mathrm{~mL}$ de solução de tiossulfato de sódio $1 \%$ com a finalidade de decloração da amostra. As mesmas foram transportadas em isopor e mantidas à $4^{\circ} \mathrm{C}$ e analisadas dentro de 24 horas.

Para os ensaios físico-químicos as amostras de água foram coletadas em frascos de $300 \mathrm{~mL}$ e realizou-se a avaliação dos parâmetros pretendidos. A determinação da quantidade de cloro, assim como a aferição da temperatura foram realizadas no momento da coleta. As análises de $\mathrm{pH}$ e turbidez foram realizadas posteriormente. As amostragens destinadas ao ensaio de determinação de metais foram adicionados de $1,5 \mathrm{~mL}$ de ácido nítrico e armazenadas sob refrigeração a $4^{\circ} \mathrm{C}$ até a leitura em absorção atômica de chama, conforme descrito no Standard methods fot the examination of water and wastewater (APHA et al., 2012).

As análises dos parâmetros físicosquímicos foram realizadas como preconiza o Standard method for examination of water and wastewater (APHA et al., 2012). Para quantificação do cloro livre foi utilizado um colorímetro portátil Pocket II Hach (Estados Unidos) de acordo com o método DPD (dialquil - 1,4 - fenilenodiamino). A turbidez das amostras foi aferida utilizando um turbidímetro portátil 2100Q HACH. O pHmetro utilizado foi PG 2000 Gehaka Digital, com soluções tampão de $\mathrm{pH}$ igual a 4,00 $\pm 0,02$ e 7,00 \pm 0,02 da Vetec Química Ltda. Todas as análises físico-química foram realizadas em duplicata.

A quantificação de metais foi realizada por espectrofotometrômetro de absorção atômica de chama modelo VARIAN AA240FS, também conforme o recomendado pelo Standard methods for examination of water and wastewater (APHA et al., 2012). Foram realizadas as análises de zinco, cádmio, ferro, cobre, manganês, alumínio e chumbo. As análises de metais foram realizadas em triplicata para todos os metais.

Com o que dispõe o Standard methods for examination of water and wastewater (APHA et al., 2012), realizou-se a análise pelo método da membrana filtrante 
para quantificação de coliformes totais e Escherichia coli. Esta metodologia se baseia na filtração de volume de água mediante pressão negativa (vácuo), utilizando uma membrana filtrante com porosidade de 0,45 $\mu \mathrm{m}$. Utilizou-se $100 \mathrm{~mL}$ de cada amostra para dispor diante da membrana, as bactérias, que apresentaram dimensões maiores que o poro da membrana, ficaram retidas na superfície, a qual foram transferidas para a placa de Petri, contendo o meio de cultura seletivo e diferencial m-Endo (Coliformes Totais) e mTec (E. coli). Pelo fenômeno da capilaridade (subida ou descida de um fluido através de um tubo ou uma espessura muito fina), o meio se difundiu com a membrana, sendo possível contato com as bactérias e após $24 \mathrm{~h}$ de incubação a $35^{\circ} \mathrm{C}$ (Coliformes totais) e $45^{\circ} \mathrm{C}$
(E. coli e bactérias termotolerantes), houve o desenvolvimento de colônias. No caso de confirmação transferiu-se as colônias para caldo lauril triptose, tendo a posterior confirmação em caldo lactosado com verde brilhante e bile $2 \%$.

\section{RESULTADOS E DISCUSSÃO}

Os resultados obtidos estão apresentados e discutidos a seguir, sendo confrontados com o que preconiza a portaria n 2914 do Ministério da Saúde (BRASIL, 2011).

A Tabela 1 apresenta as análises físico-químicas realizadas nas 21 amostras, contendo as verificações do $\mathrm{pH}$, temperatura, cloro residual livre e turbidez.

Tabela 1 - Resultados das amostras em relação a temperatura, cloro residual livre, pH e turbidez.

\begin{tabular}{|c|c|c|c|c|}
\hline Local/Amostra & pH & $\begin{array}{c}\text { Cloro Residual } \\
(\mathrm{mg} / \mathrm{L})\end{array}$ & $\begin{array}{c}\text { Temperatura } \\
\left({ }^{\circ} \mathrm{C}\right)\end{array}$ & $\begin{array}{c}\text { Turbidez } \\
(\mathbf{u T})\end{array}$ \\
\hline Caixa d'água & 6,78 & 0,02 & 19,90 & 0,09 \\
\hline Torneira & 6,90 & 0,00 & 24,50 & 0,07 \\
\hline Bebedouro 1 & 6,87 & 0,00 & 13,55 & 0,06 \\
\hline Bebedouro 2 & 6,93 & 0,02 & 14,55 & 0,06 \\
\hline Bebedouro 3 & 6,93 & 0,01 & 13,10 & 0,08 \\
\hline Bebedouro 4 & 6,92 & 0,02 & 14,50 & 0,10 \\
\hline Bebedouro 5 & 6,93 & 0,01 & 11,60 & 0,11 \\
\hline Bebedouro 6 & 7,01 & 0,00 & 10,70 & 0,16 \\
\hline Bebedouro 7 & 6,86 & 0,04 & 11,15 & 0,12 \\
\hline Bebedouro 8 & 6,89 & 0,00 & 13,75 & 0,08 \\
\hline Bebedouro 9 & 6,91 & 0,00 & 9,90 & 0,08 \\
\hline Bebedouro 10 & 6,88 & 0,00 & 15,25 & 0,09 \\
\hline Bebedouro 11 & 6,90 & 0,00 & 14,90 & 0,08 \\
\hline Bebedouro 12 & 6,85 & 0,00 & 10,65 & 0,09 \\
\hline Bebedouro 13 & 6,91 & 0,00 & 16,50 & 0,06 \\
\hline Bebedouro 14 & 7,42 & 0,01 & 9,15 & 0,21 \\
\hline Bebedouro 15 & 6,89 & 0,00 & 14,70 & 0,11 \\
\hline Bebedouro 16 & 6,91 & 0,00 & 12,80 & 0,17 \\
\hline Bebedouro 17 & 6,97 & 0,02 & 11,75 & 0,07 \\
\hline Bebedouro 18 & 7,46 & 0,01 & 22,20 & 0,07 \\
\hline Bebedouro 19 & 7,81 & 0,00 & 8,65 & 0,08 \\
\hline
\end{tabular}

Fonte: Os autores. 
Como estabelece a Portaria $n^{\circ} 2914$ (BRASIL, 2011) o pH no sistema de distribuição deve ser mantido 6 a 9,5, sendo assim, 100\% das amostras apresentaram de acordo com o estipulado pela norma. Da mesma forma, as amostras na sua totalidade apresentam temperaturas compatíveis, e a medida de turbidez variam entre 0,06 e 0,21 , sendo que o padrão para turbidez para água é de $5 \mathrm{uT}$.

No entanto, o teor de cloro residual livre em qualquer ponto do sistema de abastecimento deve ser entre 0,2 e $2 \mathrm{mg} / \mathrm{L}$. Desta forma todas as 21 amostras não apresentaram-se de acordo com o estabelecido pela Portaria. Outros estudos de monitoramento da qualidade da água destinada ao consumo humano em escolas ou instituições de ensino presentes na literatura também encontraram concentrações abaixo do estabelecido pela norma brasileira (CRONEMBERGER, 2012; SILVA, 2015).

Sendo assim, os fatores físicoquímicos da água como orienta a n 2914 (BRASIL, 2011), estão cumprindo o que dispõe o Ministério da Saúde, exceto para a concentração de cloro livre, sendo que neste, caso, apesar de não apresentar a concentração acima da máxima permitida, todas as amostras apresentaram-se abaixo da concentração mínima exigida pela norma que é de $0,2 \mathrm{mg} / \mathrm{L}$, o que pode permitir que se desenvolvam microrganismos na água sendo potencialmente prejudicial a saúde humana.

Os resultados obtidos para as análises de metais presentes nas amostras de água encontram-se apresentados na Tabela 2.

Tabela 2 - Resultados das análises de absorção atômica por chama dos metais presentes nas amostras de água.

\begin{tabular}{|c|c|c|c|c|c|c|c|}
\hline Metal/Amostra & $\begin{array}{c}\mathbf{Z n} \\
(\mathbf{m g} / \mathbf{L})\end{array}$ & $\begin{array}{c}\mathbf{C d} \\
(\mathbf{m g} / \mathbf{L})\end{array}$ & $\begin{array}{c}\mathbf{F e} \\
(\mathbf{m g} / \mathbf{L})\end{array}$ & $\begin{array}{c}\mathbf{C u} \\
(\mathbf{m g} / \mathbf{L})\end{array}$ & $\begin{array}{c}\mathbf{M n} \\
(\mathbf{m g} / \mathbf{L})\end{array}$ & $\begin{array}{c}\mathbf{A l} \\
(\mathbf{m g} / \mathbf{L})\end{array}$ & $\begin{array}{c}\mathbf{P b} \\
(\mathbf{m g} / \mathbf{L})\end{array}$ \\
\hline Poço & 0,054 & 0,020 & 0,012 & 0,001 & 0,001 & 1,806 & 0,115 \\
\hline Torneira & 0,053 & 0,030 & 0,044 & 0,011 & 0,005 & 1,868 & 0,096 \\
\hline Bebedouro1 & 0,115 & 0,009 & 0,319 & 0,031 & 0,008 & 2,039 & 0,116 \\
\hline Bebedouro2 & 0,149 & 0,014 & 0,113 & 0,027 & 0,008 & 2,158 & 0,075 \\
\hline Bebedouro3 & 0,145 & 0,008 & 0,086 & 0,037 & 0,007 & 2,204 & 0,099 \\
\hline Bebedouro4 & 0,236 & 0,013 & 0,051 & 0,044 & 0,006 & 2,230 & 0,234 \\
\hline Bebedouro5 & 0,145 & 0,016 & 0,115 & 0,048 & 0,006 & 2,310 & 0,148 \\
\hline Bebedouro6 & 0,119 & 0,019 & 0,124 & 0,031 & 0,001 & 2,434 & 0,095 \\
\hline Bebedouro7 & 0,088 & 0,014 & 0,085 & 0,019 & 0,006 & 2,561 & 0,085 \\
\hline Bebedouro8 & 0,358 & 0,012 & 0,112 & 0,049 & 0,007 & 2,625 & 0,247 \\
\hline Bebedouro9 & 0,196 & 0,017 & 0,189 & 0,019 & 0,001 & 2,767 & 0,167 \\
\hline Bebedouro10 & 0,085 & 0,028 & 0,107 & 0,001 & 0,006 & 2,779 & 0,176 \\
\hline Bebedouro11 & 0,070 & 0,018 & 0,183 & 0,001 & 0,001 & 2,816 & 0,071 \\
\hline Bebedouro12 & 0,059 & 0,019 & 0,561 & 0,010 & 0,009 & 2,993 & 0,083 \\
\hline Bebedouro13 & 0,066 & 0,013 & 0,190 & 0,001 & 0,007 & 2,971 & 0,110 \\
\hline Bebedouro14 & 0,232 & 0,014 & 0,115 & 0,001 & 0,008 & 3,051 & 0,105 \\
\hline Bebedouro15 & 0,119 & 0,035 & 0,057 & 0,019 & 0,001 & 3,120 & 0,077 \\
\hline Bebedouro16 & 0,095 & 0,019 & 0,203 & 0,015 & 0,004 & 3,276 & 0,083 \\
\hline Bebedouro17 & 0,142 & 0,015 & 0,074 & 0,017 & 0,004 & 3,295 & 0,128 \\
\hline Bebedouro18 & 0,107 & 0,008 & 0,114 & 0,027 & 0,001 & 3,486 & 0,230 \\
\hline Bebedouro19 & 0,073 & 0,012 & 0,093 & 0,007 & 0,001 & 3,463 & 0,851 \\
\hline Font Ora & & & & & & \\
\hline
\end{tabular}

Fonte: Os autores. 
A grande maioria dos trabalhos presentes na literatura sobre monitoramento da qualidade da água destinada ao consumo humano em escolas e instituições de ensino, está focado, em análises microbiológicas e ensaios físico-químicos, tais como $\mathrm{pH}$ e cloro. Porém, no presente trabalho, foi possível detectar outro contaminante altamente nocivo que pode estar presente na água, os metais. As análises de metais realizadas, revelaram que somente 4 dos 7 metais averiguados apresentaram concentrações permitidas os valores máximo permitido (VMP) segundo a Portaria 2914 (BRASIL, 2011). A Tabela 3 apresenta os VMP dos metais analisados neste trabalho.

Tabela 3 - VMP segundo a Portaria 2914 para os metais analisados no presente trabalho

\begin{tabular}{cc}
\hline Metal & VMP $(\mathbf{m g} / \mathbf{L})$ \\
\hline $\mathrm{Zn}$ & 5 \\
$\mathrm{Cd}$ & 0,005 \\
$\mathrm{Fe}^{*}$ & 0,3 \\
$\mathrm{Cu}$ & 2 \\
$\mathrm{Mn}$ & 0,1 \\
$\mathrm{Al}$ & 0,2 \\
$\mathrm{~Pb}$ & 0,01 \\
\hline
\end{tabular}

Fonte: Os autores

As concentrações de manganês, zinco e cobre apresentaram-se de acordo com o estipulado pela Portaria 2914 do Ministério da Saúde (BRASIL, 2011), no entanto, as concentrações de ferro, cádmio, chumbo e o alumínio apresentaram-se superiores aos valores máximos permitidos recomendados.
Para os padrões de potabilidade o cádmio deve ter $0,005 \mathrm{mg} / \mathrm{L}$, porém as amostras coletadas as concentrações variaram de 0,008 a $0,035 \mathrm{mg} / \mathrm{L}$, ou seja, até 7 vezes maior do que o valor máximo permitido. $\mathrm{O}$ nível máximo de chumbo permitido é de 0,01 $\mathrm{mg} / \mathrm{L}$, porém nos resultados obtidos teve $100 \%$ das amostras com o nível acima de 0,01 mg/L, sendo a concentração de 0,071 a $0,85 \mathrm{mg} / \mathrm{L}$, sendo neste caso até 85 vezes maior do que o valor máximo permitido.

A presença de ferro em água recomendado pelo ministério da saúde é de 0,3 $\mathrm{mg} / \mathrm{L}$ de acordo com o padrão organoléptico de potabilidade. Duas amostras $(9,52 \%)$ foram detectadas com o valor superior ao recomendado. Em relação também ao padrão organoléptico de potabilidade, a concentração de alumínio na água para consumo é recomendado de até no máximo $0,2 \mathrm{mg} / \mathrm{L}$ de acordo com a Portaria 2914 do Ministério da Saúde (BRASIL, 2011). Porém, o alumínio foi o metal que apresentou maior concentração, e todas as amostras apresentaram concentrações superiores ao estipulado pela portaria, variando de 1,806 a 3,486 mg/L, ou seja de 9 a 17 vezes maior do que o VMP.

As análises feitas para a quantificação de metais presentes em água demonstraram irregularidades, representando mudanças organolépticas, e risco a saúde humana. Os metais quando ingeridos em quantidades acima dos VMP podem causar doenças como câncer, doenças cardiovasculares, problemas renais, 
problemas neurotóxicos, doenças neurodegenerativas, Alzheimer, etc (DIETER et al., 2005; JÄRUP, 2003; KAWAHARA et al., 2011; WASSERMAN et al., 2006; ZATTA et al., 2003).

Foram realizadas análises para identificação de dois grupos de bactérias, coliformes totais utilizadas como indicador de potabilidade e indicador geral das condições higiênico-sanitária da água, e a E. coli sendo indicadora de contaminação fecal ou de condição higiênica insatisfatória. Os resultados das amostras de água em relação a coliformes totais e E. coli encontram-se na Tabela 4.

Tabela 4 - Resultado das amostras em relação a presença de bactérias (Coliformes totais e E. coli) em $100 \mathrm{~mL}$ de água.

\begin{tabular}{ccc}
\hline Amostra & Coliformes Totais & E. coli \\
\hline Poço & Ausente & Ausente \\
Torneira & 4 colônias & Ausente \\
Bebedouro 1 & 5 colônias & Ausente \\
Bebedouro 2 & 5 colônias & Ausente \\
Bebedouro 3 & 3 colônias & Ausente \\
Bebedouro 4 & 1 colônia & Ausente \\
Bebedouro 5 & Ausente & Ausente \\
Bebedouro 6 & Ausente & Ausente \\
Bebedouro 7 & Ausente & Ausente \\
Bebedouro 8 & Ausente & Ausente \\
Bebedouro 9 & Ausente & Ausente \\
Bebedouro 10 & Ausente & Ausente \\
Bebedouro 11 & Ausente & Ausente \\
Bebedouro 12 & 1 colônia & Ausente \\
Bebedouro 13 & Ausente & Ausente \\
Bebedouro 14 & Ausente & Ausente \\
Bebedouro 15 & Ausente & Ausente \\
Bebedouro 16 & Ausente & Ausente \\
Bebedouro 17 & Ausente & Ausente \\
Bebedouro 18 & Ausente & Ausente \\
Bebedouro 19 & Ausente & Ausente \\
\hline
\end{tabular}

Fonte: Os autores

A presença de colônias de coliformes totais foi relatada em $28,57 \%$, sendo $100 \%$ das amostras com ausência de E. coli. No que diz o ANEXO I da Portaria No 2914 do Ministério da Saúde (BRASIL, 2011), sobre padrão microbiológico de água para consumo humano, para indicador de integridade do sistema de distribuição (reservatório e rede), onde este sistema deve abastecer menos de 20 mil pessoas, apenas uma das amostras pode ter resultado positivo no mês para coliformes totais e ausência de E. coli em $100 \mathrm{~mL}$, sendo que esta análise deve ser feita regularmente. Portanto, o resultado bacteriológico para contaminação fecal foi satisfatória porém para as condições de potabilidade estipulado pela Portaria No 2914 do Ministério da Saúde (BRASIL, 2011) e condições higiênicosanitária da água foram insatisfatórias e não foram satisfeitas.

$\mathrm{Na}$ literatura existem extensos estudos sobre a qualidade microbiológica da água em escolas e instituições de ensino nas mais diferentes regiões do Brasil, que relatam a alta incidência de águas contaminadas (CARDOSO; et al.; NEVES et al., 2016; SILVA, 2015; SOUZA et al., 2015). Estudos realizados em 36 instituições de ensino em águas de cantinas e cozinhas na Bahia, encontraram $25 \%$ das amostras em desacordo com a portaria (ROCHA et al., 2010). Outro estudo realizado em Minas gerais, foram coletadas amostras de água destinada ao consumo humano de escolas, e $14 \%$ apresentaram-se com qualidade microbiológica insatisfatória (FARIA et al., 2013), podendo-se concluir que não se trata de um problema local. 
Sabe-se que além da poluição direta das fontes deá gua e dos sistemas de distribuição que podem ocorrer ocasionalmente, as condições higi ênicosanitárias e conservaç ão dos reservatórios de água podem ser responsáveis pela veiculação de agentes patogênicos, assumindo um importante papel na contaminação ou recontaminação da água. Ocorrendo a transmissão de micr organismos caso estes locais estejam em condições in adequadas de higiene e conservação (FARIA et al., 2013). Portanto, recomenda-se melhores processos de higienização e aumentar a concentração de cloro para o estabelecido por lei de acordo com a Portaria No 2914 do Ministério da Saúde (BRASIL, 2011).

\section{CONCLUSÕES}

Os dados apurados nesta pesquisa demonstram que as amostras de água analisadas não apresentaram a qualidade da água adequada e devem ser tomadas medidas preventivas em relação à sua qualidade. Os resultados de $\mathrm{pH}$, turbidez, temperatura, a concentração dos metais zinco, cobre e manganês apresentaram-se dentro da normalidade, assim como a ausência de $E$. coli, o qual indicou que não haver contaminação fecal, estando de acordo com o estipulado pela portaria $n^{\circ} 2914$ do Ministério da Saúde (BRASIL, 2011).
Os metais que apresentaram concentrações acima do VMP são de grande risco à saúde humana, devendo ser tomadas medidas preventivas, como a instalação de filtros nos bebedouros. Em relação às análises bacteriológicas, verificou-se a presença de coliformes totais que pode ser atribuído à baixa concentração de cloro residual. Os resultados desta pesquisa alertam para melhoria dos processos de higienização dos bebedouros e aumento da concentração de cloro para faixa recomendada portaria $\mathrm{n}^{\circ} 2914$ do Ministério da Saúde (BRASIL, 2011), assegurando assim uma água de maior confiabilidade para consumo humano.

\section{AGRADECIMENTOS}

Ao Programa Institucional de bolsas de Iniciação científica (PIBIC) do Conselho Nacional de Desenvolvimento Científico e Tecnológico (CNPq) e ao Instituto de Ciência, Tecnologia e Inovação (ICETI) pelo apoio financeiro.

\section{REFERÊNCIAS}

APHA; AWWA; WEF. Standard Methods for the Examination of Water \& Wastewater: American Public Health Association, 2012. $1496 \mathrm{p}$.

BRASIL. Portaria $n^{\circ}$ 2.914, de 12 de dezembro de 2011. Dispõe sobre os procedimentos de controle e de vigilância da qualidade da água para consumo humano e seu padrão de potabilidade. Ministério da Saúde, 2011. 
CARDOSO;, R. C. V.; ALMEIDA;, R. R. C. C.; GUIMARÃES; A. S. G.; GÓES; J. Â. W.; SILVA; S. A.; SANTANA;, A. A. C.; HUTTNER;, L. B.; JUNIOR;, P. N. O. V.; FIGUEIREDO, K. V. N. A. Qualidade da água utilizada em escolas atendidas pelo Programa Nacional de

Alimentação Escolar (PNAE), em SalvadorBA. Revista Instituto Adolfo Lutz, v. 66, n. 3, p. 5, 2007.

CRONEMBERGER, S. S. L. J. W. D. S. M. G. D. O. Análise da qualidade química e microbiológica da água consumida em escolas públicas municipais da zona norte de Teresina - PI. In: XVII CONGRESSO BRASILEIRO DE ÁGUAS SUBTERRÂNEAS, 2012, Bonito-MS (Brasil), p.

DIETER, H. H.; BAYER, T. A.; MULTHAUP, G. Environmental Copper and Manganese in the Pathophysiology of Neurologic Diseases (Alzheimer's Disease and Manganism). Acta hydrochimica et hydrobiologica, v. 33, n. 1, p. 72-78, 2005.

DODDS, W. K.; PERKIN, J. S.; GERKEN, J. E. Human Impact on Freshwater Ecosystem Services: A Global Perspective.

Environmental Science \& Technology, v. 47, n. 16, p. 9061-9068, 2013.

FARIA, T.; PAULA, R. A. O.; VEIGA, S. M. O. M. Qualidade microbiológica da água para consumo humano em unidades de alimentação escolar. Revista da Universidade Vale do Rio Verde, v. 11, n. 1, p. 10, 2013.

FU, H.-Z.; WANG, M.-H.; HO, Y.-S. Mapping of drinking water research: A bibliometric analysis of research output during 1992-2011. Science of The Total Environment, v. 443, n., p. 757-765, 2013.

IKEM, A.; ODUEYUNGBO, S.; EGIEBOR, N. O.; NYAVOR, K. Chemical quality of bottled waters from three cities in eastern Alabama. Sci Total Environ, v. 285, n. 1-3, p. 165-175, 2002.
JÄRUP, L. Hazards of heavy metal contamination. British Medical Bulletin, v. 68, n. 1, p. 167-182, 2003.

KAWAHARA, M.; KATO-NEGISHI, M. Link between Aluminum and the Pathogenesis of Alzheimer's Disease: The Integration of the Aluminum and Amyloid Cascade Hypotheses. International Journal of Alzheimer's Disease, v. 2011, n., p. 276393, 2011.

LIU, L.; JOHNSON, H. L.; COUSENS, S.; PERIN, J.; SCOTT, S.; LAWN, J. E.; RUDAN, I.; CAMPBELL, H.; CIBULSKIS, R.; LI, M.; MATHERS, C.; BLACK, R. E. Global, regional, and national causes of child mortality: an updated systematic analysis for 2010 with time trends since 2000. The Lancet, v. 379, n. 9832, p. 2151-2161, 2012.

NEVES, A. A. M.; MARINHO, L. L. A.; FERREIRA, C. D. S.; COUTINHO, M. G. S.; JULIÃO, M. S. R. D. S.; FONTENELLE, R. O. D. S. Avaliação físico-química e parasitológicade águas de bebedouros de uma instituição de ensino superior de Sobral-CE. Revista da Universidade Vale do Rio Verde, v. 14, n. 2, p. 8, 2016.

OMS. Guidelines for Drinking-Water Quality. 2011.

ROCHA, E. S.; ROSICO, F. S.; SILVA, F. L.; LUZ, T. C. L. S. D.; FORTUNA, J. L. Análise microbiológica da água de cozinhas e/ou cantinas das instituições de ensino do município de Teixeira de Freitas (BA).

Revista Baiana de Saúde Pública, v. 34, n. 3, p. 12, 2010.

SILVA G. D. A. D. T. J. L. C. S. S.-O. E. S. E. Avaliação da qualidade da água em três Escolas Públicas da Cidade de Macapá, Amapá. Biota Amazônia, v. 5, n. 1, p. 7, 2015.

SOUZA, C. N. A. B. D.; OLIVEIRA, E. L. D.; AVELINO, M. B.; RODRIGUES, R. C. D.; RODRIGUES, M. S. P.; FERREIRA, M. A. N. F.; MEDEIROS, W. R. Qualidade da água consumida em unidades de educação 
infantil no município de Mossoró-RN. Revista Ciência Plural, v. 1, n. 2, p. 11, 2015.

WANG, M.-H.; YU, T.-C.; HO, Y.-S. A bibliometric analysis of the performance of Water Research. Scientometrics, v. 84, n. 3, p. 813-820, 2010.

WASSERMAN, G. A.; LIU, X.; PARVEZ, F.; AHSAN, H.; LEVY, D.; FACTOR-

LITVAK, P.; KLINE, J.; VAN GEEN, A.;

SLAVKOVICH, V.; LOIACONO, N. J.;

CHENG, Z.; ZHENG, Y.; GRAZIANO, J. H.

Water manganese exposure and children's intellectual function in Araihazar, Bangladesh. Environ Health Perspect, v. 114, n. 1, p. 124-129, 2006.

ZATTA, P.; LUCCHINI, R.; VAN RENSBURG, S. J.; TAYLOR, A. The role of metals in neurodegenerative processes: aluminum, manganese, and zinc. Brain Res Bull, v. 62, n. 1, p. 15-28, 2003. 